Allgemeines Statistisches Archiv 88, 303-326

(C) Physica-Verlag 2004, ISSN 0002-6018

\title{
Hedonic price indices for the Paris housing market
}

\author{
By Raimond Maurer, Martin Pitzer, and Steffen Sebastian*
}

Summary: In this paper, we calculate a transaction-based price index for apartments in Paris (France). The heterogeneous character of real estate is taken into account using an hedonic model. The functional form is specified using a general Box-Cox function. The data basis covers 84686 transactions of the housing market in 1990:01-1999:12, which is one of the largest samples ever used in comparable studies. Low correlations of the price index with stock and bond indices (first differences) indicate diversification benefits from the inclusion of real estate in a mixed asset portfolio.

KEYwords: Real estate investments, hedonic, index construction, Box-Cox transformation, diversification. JEL C43, C51, O18, R20.

\section{INTRODUCTION}

The various participants in the real estate market have a substantial interest in the development of property prices and tracing them back to common causal factors. If investors, developers or other participants wish to judge the attractiveness of individual real estate projects, an assessment of the (uncertain) prices in the market segment should constitute an essential element in the decision process. Especially institutional investors, such as insurance companies, pension or investment funds, require reliable information concerning the development of real estate prices. With regard to questions of asset allocation (i.e. the distribution of a given budget among the main investment sectors, such as stocks, bonds and real estate), information about returns and risk profiles of real estate and their correlation with other types of investment is of central importance. Finally, the government also requires information regarding price changes on the real estate markets, for example, to assess, plan and regulate the effectiveness of government intervention measures.

There are basically three different approaches to the construction of real estate indices, in order to match the need of information about price developments. Besides indices that analyze returns on the real estate of institutional investor portfolios (appraisal-based indices) and the rate changes for shares of real estate investment companies on the stock market, transaction-based indices play an important role in real estate literature. (For an overview,

Received: 02.12.2002 / Revised: 19.04.2004

* This paper has been developed at the Research Program 'Real Estate Finance' at Goethe-University of Frankfurt/Main (Germany). We gratefully acknowledge iii Internationales Immobilien Institut, IVG Holding AG and Stiftung Rheinische Hypothekenbank for their financial support. For further information, see www.real-estate-finance.de. We thank the participants of the 8th Conference of the European Real Estate Society (ERES), the International Conference of the American Real Estate and Urban Economics Association (AREUEA), the 10th Global Finance Conference 2003 and the anonymous referees for helpful comments, which improved the paper substantially. 
see Bender et al., 1994, p.523-527; Fisher et al., 1994; Hoesli and MacGregor, 2000, p.61-71; Maurer et al., 2002.) The latter are based on an analysis of actual market prices and the characteristics of completed transactions in real estate within a specific time-period. The construction of such an index however, due to the heterogeneous nature of the real estate and the infrequency of transactions, is fraught with difficulties. If transactions are observed at different points in time, different prices do not necessarily indicate changes in the price level of the observed market sector. Rather, such differences may be due to the location, size, or structural condition of the property in question. Therefore, the construction of a transaction-based real estate index must consider qualitative differences in the property being analyzed.

Within the class of transaction-based real estate indices, again, three different approaches can be distinguished. One possibility is to calculate the average price per square meter of all transactions in a particular property market segment, within the historical period being examined. This simple method, however, does not adequately take into account the temporal differences in the quality of the traded objects. Further advancements in this approach attempt to filter out some of the heterogeneity of property assets by ascertaining average prices for those segments that are sufficiently homogeneous in terms of location, function and other possible characteristics. However, the problem is that there are not always enough transactions in every period segment respectively, in order to present statistically reliable statements regarding price levels.

Another alternative is to restrict the analysis to properties that were sold at least twice (repeat sales method) within the entire observational period. In this case, it is possible to directly compare property prices between different points in time. However, the precondition for this is that, within this period, no structural improvements have been undertaken that would influence the property value. Additionally, significant changes in the surrounding area, such as an improvement (or deterioration) in the local infrastructure increase the difficulty in ascertaining value changes on the basis of developments over time. This difficulty only increases with the length of the period of study (see Thion et al., 2000, p.6-7). Another possibility is to limit the study to objects that have been sold two or more times in comparatively short time-periods. Real estate however, is characterized as usually involving more extended periods of investment. If only real estate is considered that has often been sold, it is questionable as to whether it can be regarded as representative for the market under study (see Bender et al., 1994, p. 525; Gatzlaff and Haurin, 1997).

The third approach, which is the focus of this paper, is to construct a quality-adjusted property price index via the so-called hedonic approach. The hedonic approach attempts to solve the problem of heterogeneity by using an econometric model, which analyzes value-influencing factors of properties separately from temporal factors of influence. The theoretical foundation of this method was developed by Lancaster (1966) and Rosen 
(1974), and based on the assumption that the value of a good can be completely described using a vector of distinctly analyzed characteristics. Following hedonic theory, the value of a property is a function of structural and environmental attributes of the building, such as location, condition or size, and the period in which the transaction takes place. This allows for the separation of otherwise 'naturally' heterogeneous property types into their homogeneous attributes, and at the same time, determination of their influence on the value of the objects.

The goal of this paper is to present the theoretical basis for the construction of hedonic real estate indices, as well as to empirically apply this approach using extensive data to the housing market in Paris. As the second largest city in Europe and the capital of France, which is one of the leading economies of the world, Paris represents one of the most important real estate markets in the world. With about 11 million inhabitants, the region Île de France and its surrounding suburbs contain about $20 \%$ of the population of France. Out of this, the département 75 (Paris without suburbs), which constitutes the focus of the following study, has a population of about 2 millions. The residential area consists almost exclusively of multi-family houses, which have mostly been divided up into condominiums. These housing areas are very heterogeneous in nature, with regard to their age and structural condition. They vary from medieval quarters in the city center, to newly built sections.

\section{Methodological Basis}

The hedonic method is statistically based on a multiple regression model, whereby the observed transaction prices of a (sufficiently large) number of properties are shown as endogenous and the value determining attributes as exogenous variables. ${ }^{1}$ While the attributes are not sold separately, the resulting regression coefficients yield the marginal contribution of each attribute to the sales price for the respective property. Both, physical characteristics of the property itself (size, number of rooms, existence of elevators, etc.), as well as location factors (location criteria, infrastructure data) are considered in hedonic models (see Behring et al., 1988, p. 100-102). In general, the regression model takes the following form

$$
p=f(x, \beta)+\varepsilon,
$$

where

$p=$ vector of observed transaction prices,

$x=$ matrix of characteristics,

$\beta=$ vector of coefficients,

$\varepsilon=$ white noise.

\footnotetext{
1 For an overview of methods for the construction of hedonic indices, see Mark and Goldberg (1984).
} 
The regression parameters $\beta$ respectively $\beta_{i}$ reflect the price of the attribute $x_{i}$, and are thus called hedonic prices. Consideration of the temporal development can be accomplished by two different approaches. In the so-called direct method, the vector $x$ include not only real estate specific characteristics (location, function, size), but also dummy time-variables for the transaction period. Hereby, it is assumed that the influence of the characteristics on the value of the real estate remains constant over the period of study (see Zürcher Kantonalbank, 1996, p. 34; Kuo, 1997, p. 113).

Following the so-called indirect methods, a separate regression equation for each observed period (year, quarter, month) is estimated. As the regression coefficients (i.e. the hedonic price of the different attributes) in every period can be estimated, this approach has the advantage that an altering influence of an attribute on the value of an apartment can also be taken into consideration. However, in most empirical studies the direct method is chosen since a sufficient number of transactions is not available for all timeperiods, which may lead to insignificant parameter coefficients (see Bender et al., 1994, p. 526-527). With limited data, there will always be the trade-off between time-flexible but potentially insignificant results and constant, but more likely significant coefficient estimations. ${ }^{2}$ Here, the indirect method would lead to insignificant results for several factors, especially for location. We, therefore, apply only the direct method to calculate the hedonic index.

If the hedonic price of the value-determining factors is determined according to one of these methods, a price index for a typical real estate portfolio can be constructed. The bundle of qualities represented through this portfolio is then evaluated in every period according to the hedonic model. Hereby every portfolio that is considered representative can be applied, including, e.g., the entire amount of a market.

Apart from the specification of the value-influencing attributes, it is necessary to determine which function-type is applied in explaining the connection shown in equation one. Often linear, semi-logarithmic or log-linear models are chosen. These are particularly characterized as being easily interpretable, and the estimated parameters as possessing a direct economic meaningfulness. With the linear model, the parameters give absolute prices for the unit of the attributes; with semi-logarithmic models, the coefficients of a variable are equal to the percentage effect of that variable being explained. ${ }^{3}$ With log-linear functions, the price-elasticity of the properties are displayed in terms of a relative change in the respective characteristic amounts. $^{4}$

\footnotetext{
2 The influences of an attribute may not only alter in time, but also in space or in other dimensions. For example, the existence of a parking space is most likely to have a different influence on the value of an apartment in the Central Business District than to a comparable object in an area where parking space is less rare. This problem can be solved by using compound indicator variables. For a discussion, see Rogers (2000).

3 This interpretation only holds for continuous variables. For dummy variables, see Halvorsen and Pollakowski (1980).

4 Whereby only the metric variables can be subjected to a logarithm, as dummy variables can approach the value zero and the logarithm of zero is not defined. Hence, the
} 
Yet, the assumption that the linear, semi-logarithmic, or log-linear function-regulation correctly describes the influence of the value-determining factors on the real estate prices and/or their changes, is not a priori justified (see Goodman, 1978, p.476; Halvorsen and Pollakowski, 1981, p. 47). The choice of a particular function-type is equivalent, to the arbitrarily determined restriction brought about by the limitations of the model. One possibility of determining the function form in an endogenous manner is provided by Box and Cox (1964). Here, a regression model of the following type is the starting-point

$$
p_{i}^{(\theta)}=\beta_{0}+\sum_{j=1}^{k} \beta_{j} x_{j i}^{(\lambda)}+u_{i},
$$

where the price $p_{i}$ of a property is transformed through the parameter $\theta$ to

$$
p^{(\theta)}= \begin{cases}\frac{p^{\theta}-1}{\theta} & (\theta \neq 0), \\ \ln p & (\theta=0),\end{cases}
$$

and analogously, the exogenous variables $x_{j i}^{(\lambda)}$ with the parameter $\lambda$ to ${ }^{5}$

$$
x^{(\lambda)}= \begin{cases}\frac{x^{\lambda}-1}{\lambda} & (\lambda \neq 0), \\ \ln x & (\lambda=0) .\end{cases}
$$

The parameters $\theta, \lambda$ and $\beta$ of the model in Equation 2 can be determined via a maximum likelihood estimation, whereby the following maximum likelihood function is maximized

$$
L_{\text {max }}=(\theta-1) \sum_{i=1}^{n} \ln p_{i}-\frac{n}{2} \ln \left(\frac{S S R(\theta, \lambda, \beta)}{n}\right),
$$

where SSR is the sum of squared residuals. According to which values $\theta$ and $\lambda$ take, the function-form of the model also changes. A linear function is obtained if $\theta=\lambda=1$, a log-linear if $\theta=\lambda=0$, and a semi-logarithmic function if $\theta=0$ and $\lambda=1$. If, however, values other than 0 and 1 are obtained for the parameters $\theta$ and $\lambda$, then the parameter-estimators $\hat{\beta}_{i}$ of the Box-Cox model do not possess a direct economic meaningfulness. The interpretation of the hedonic prices is made more difficult by the transformation of the variables, since the calculated coefficients are artificial, to a certain extent (see Cassel and Mendelsohn, 1985, p. 137, 139). Also, exogenous variables, with which the larger part of the variations in the endogenous variables can

parameters of the dummy variables are not elasticities but rather semi-elasticities. With $p$ as regressand, they give the absolute change of the real estate prices if the respective quality is present, respectively, if the regressand is $\ln (p)$, the parameters express the relative changes.

5 Dummy variables cannot be transformed, as these can only assume the values 0 or 1, see Cassel and Mendelsohn (1985, p. 138). 
be explained, dominate in the determination of the optimal transformation parameters. Thereby, it is possible that the effect of an exogenous variable, which is less important for the total model, is incorrectly considered. ${ }^{6}$

This clarifies the conflict of aims between an optimal fit of the model and the determination of meaningful hedonic prices for real estate qualities. Whether one makes use of the Box-Cox transformation, finally depends on the object of investigation. If the main interest lies in identifying the influence of individual qualities of properties on their prices, (for example, in the analysis of the risk-structure of real estate portfolios), then the BoxCox function may be inadequate. In this case, the simplicity of the model structure and the immediate interpretability of the model's results in economic terms should be given priority (see Box and Cox, 1964, pp. 213). Still, the use of the Box-Cox transformation may in this case help to determine the functional form objectively; for example whether a linear, log-linear or semi-logarithmic function should be applied.

However, it is the purpose of an index to present a comprehensive overview of the actual price development on the real estate market, and not to separate the influence of one quality. For the selection of the hedonic price functions, which form the basis of the index, the Box-Cox model should be granted priority (see Cassel and Mendelsohn, 1985, pp. 137).

\section{Previous applications of Hedonic indices}

The hedonic method for the construction of real estate indices has been in particular in the USA the object of many empirical studies. The work of Haas (1922) is regarded as being the first application of hedonic indices (see Colwell and Dilmore, 1999). Haas (1922) determines the prices of agricultural areas in Minnesota (USA) in the time period 1916-1919 on the basis of a linear regression model. In another early work, Waugh (1929) provides evidence of the factors influencing vegetable prices. The term 'hedonic' goes back to Court (1939), who examines price development in the automobile sector. Griliches (1961) uses again a hedonic model to track automobile prices. Bailey et al. (1963) analyzed various regression techniques on the basis of property sales prices in St. Louis (USA) in the years 1937-1959. Fisher et al. (1994) compared various approaches, whereby a hedonic index for the time period 1979-1992 was calculated. The data basis for this study are sales from the portfolios of institutional investors, insofar as they are registered in the NCREIF-Index. The appropriateness of publicly available data for the construction of hedonic and other types of indices is examined by Kiel and Zabel (1997) on the basis of the American housing survey for the

\footnotetext{
6 See Cassel and Mendelsohn (1985, p. 136). Also the standard errors of the OLS estimator $\beta_{i}$ have been calculated on the assumption that $\theta$ and $\lambda$ are known. In fact, $\theta$ and $\lambda$ are in the Box-Cox model estimated parameters. The application of the estimate functions for $\theta$ and $\lambda$ leads to the estimated standard errors of $\beta_{i}$ being systematically underestimated. Therefore, statistical tests, such as $t$-statistics, are no longer valid, see Greene (1993, p. 330-333).
} 
time period 1975-1991 in selected cities. In a more recent study, Wolverton and Senteza (2000) show the advantages of hedonic indices through other methods.

In Europe, several studies exist on hedonic indices, in particular for Switzerland. Bender et al. (1994) constructed hedonic indices using linear, semi-logarithmic and log-linear functions on the basis of transactions in housing properties in the canton Geneva, in the time period 1978-1992. In a study by the Zürcher Kantonalbank (1996) hedonic indices are calculated on a yearly basis for housing properties in the canton Zurich. Hoesli et al. (1997) draw up indices for three real estate brackets in Geneva based on 304 transactions following different methods.

In the above-mentioned studies, parameter estimates are mostly undertaken on the basis of standard functions such as linear, semi-logarithmic or log-linear functions. However, the results of several empirical studies are not in-line with these function forms. Goodman (1978), for example, explicitly excludes the application of this standard form for a set of data of 1835 transactions based on a Box-Cox transformation. Also Milton et al. (1984) prove, based on 917 transactions of properties in Northwest Florida (USA), that standard functions, unlike Box-Cox transformations, can lead to distorted estimates for real estate prices. Coulson and Robins (1987) and Cropper et al. (1988) examine other standard functions besides the abovementioned and reach the conclusion for the observed set of data that a Box-Cox transformation represents the appropriate technique for ascertaining hedonic price functions. An application of the Box-Cox transformation to European real estate is found in Lansink and Thijssen (1998), who study prices for agricultural areas in the Netherlands in the years 1970-1988.

Most of the studies described above only analyze a few hundred transactions. The reason for this is that data stem from non-public sources such as mortgage documents of individual banks or from the sales-figures of selected institutional investors, as sales prices and other figures, necessary for hedonic indices, are not usually registered centrally. Therefore, the representativeness of the sample for the entire market is not guaranteed. Additionally, the small sample size leads to limitations on the number of the parameters to be estimated.

One exception is the price index Notaires-INSEE calculated by the Chambre Interdépartementale des Notaires de Paris (CINP), together with the Institut National de la Statistique et des Etudes Economiques (INSEE). With a central registration of a large part of all sales processes by a neutral institution, a high level of representativeness can be assumed. From this, hedonic indices based on a log-linear model are calculated for several French cities (see Dubujet, 2000; Laferrère, 2001).

Our study is concentrated on Paris as one of the most important real estate locations in Europe. Unlike the construction of the Notaires-INSEE index, we undertake an optimization of the function-form through a BoxCox transformation. Furthermore, some problems with incomplete data are treated differently in this study. 


\section{Description of the DAta Situation}

Real estate purchases in France must be, by law, attested by a notary. ${ }^{7}$ Since 1990 the certified data are supposed to be passed on to the Chambre Interdepartementale des Notaires de Paris (CINP). This data is available in digital form to the public, thereby creating a data basis of international standing. ${ }^{8}$ In the following table the percentage of the registered transactions among all sales in Paris is listed. Accordingly, the percentage of all transactions in the period of study rose from almost $40 \%$ in 1990 to over $75 \%$ of all apartment sales in Paris in 1999.

\begin{tabular}{|c|c|c|c|c|c|c|c|c|c|}
\hline 1990 & 1991 & 1992 & 1993 & 1994 & 1995 & 1996 & 1997 & 1998 & 1999 \\
\hline 39.18 & 48.30 & 60.06 & 62.50 & 69.38 & 71.90 & 66.45 & 77.30 & 76.76 & 77.33 \\
\hline
\end{tabular}

TABLE 1. Percentage of transactions documented in the data basis in the total of all real estate sales in Paris (département 75 ) in \%.

For every transaction, according to the CINP approximately 100 different characteristics can be ascertained. Despite this variety, some statements are still missing, which can be essential in determining the price of a property. The most essential characteristics of an apartment are in general the surface in $\mathrm{m}^{2}$, the location respectively the quality of the location, the preservation and the equipment of the property under consideration. Furthermore, very important is the fact whether it is occupied by a tenant or free. For example, the data set contains information about the year of construction, the existence of central heating, elevator, garden or terrace and the occupancy status. The location is ascertained as one of 80 quartiers and, in addition, as one of 20 arrondissements. However, information regarding the quality of the location or the degree of property preservation are not directly considered in the data gathering process.

First, in order to exclude atypical events, a transaction is only considered in case of a 'vente de gré à gré', i.e. the conclusion of a sales contract in which the unrestricted property (pleine propriété) is conferred through the payment of a predetermined sum. Hereby, compulsory auctions, sale against a life annuity are not considered. Commercially used apartments have been excluded from the sample as well. These types of transactions constitute about $3 \%$ of all observations. The remaining sample consists of 237704 observations.

Furthermore, regarding the characteristics under consideration, the data is incomplete since both the investigation and the passing on of the information occurred voluntarily. ${ }^{9}$ This necessitates further preparation of the

\footnotetext{
7 For an overview of the real estate market in Paris and the legal framework, see Welsh (1992), Sebastian (1996), IEIF (1999), Hök (2000).

8 All data are extracted from CD-BIEN Base d'Informations Economiques Notariales, Version B, Edition No. 18 from July 2000.

9 Statements regarding the date of purchase and sales price existed in all cases, as well as the number of service rooms and ('chambre de bonne') and bathrooms. It would
} 
data. The problem of missing data is widely discussed in the literature. ${ }^{10}$ While treating the problem correctly the missing data mechanism should be taken into account. In this study, the missing data problem is taken into account using conventional methods as imputation (i.e. replacing the missing observation) and elimination. In detail, elimination was applied as follows: (i) The sets of data have been excluded from the sample as faulty or (ii) the characteristic was not included in the regression equation. ${ }^{11}$ Both approaches can severely affect the results. The exclusion of sets of data can lead to an atypical selection and to a distortion in the sample. ${ }^{12}$ On the other hand, the omission of significant variables in a regression, i.e. underfitting, may lead to distortions of the estimators (see Greene, 1993, pp. 245).

We have therefore proceeded as following. As we use the surface for the Box-Cox transformation, 31419 observations, where the surface in $\mathrm{m}^{2}$ is not given, are excluded from the sample. ${ }^{13}$ In about 32000 sets of data statements are lacking with regard to either the number of garages, a statement of the property being old or new, ${ }^{14}$ the space in square meters, the location or the year of construction. It must be determined therefore whether a reduced sample of approximately 206000 transactions can be considered representative of the basic total. Therefore, in a first approach, mean and standard deviation of all parameters are calculated. Secondly, regressions

appear that in view of the incomplete nature of other data, that in fact some sets of data were incomplete, but in the data bank were given the value 'zero'. A differentiation is in this case not possible.

10 For an overview, see Afifi and Elashoff (1966), Rubin (1976), Dempster et al. (1977), Schafer (1997).

11 For the first approach (i), it is assumed that the data about some characteristics are either missing at random or missing completely at random. The definition of missing mechanisms goes back to Rubin (1976). Data are called missing at random (MAR), if characteristics are missing independently of the value of the variable, and observed at random (OAR), if the missing occurs independently of the values of other variables. If data are both MAR and OAR, they are called to be missing completely at random (MCAR).

12 Chi-square tests for equality of distributions indicate in all examined cases a significantly different distribution after the exclusion of data from the sample. A test applied on equality of mean and standard deviation leads to equivalent results.

13 For the construction of the Notaires INSEE index a correction of the surface area figures has been undertaken in addition. According to the 'Carrez' law, exact figures must be given for the surface area of an apartment since June, 1997; the seller is responsible for any exaggerated figures. Dubujet (2000) records that since this point in time, on average a $4 \%$ decrease in surface area figures has taken place, and therefore, recommends a correction procedure on the basis of an econometric model, according to which the surface areas of all apartments that had been sold before July 1997 (see Dubujet, 2000, pp. 9f.) are corrected. Following the supposition that the surface areas have been correctly declared since the 'Carrez' laws having taken effect, this has meant that the price changes in the third quarter 1997 are upwardly distorted. The development of the index before and after this period is unaffected by the 'Carrez' law accordingly. Since this effect, in our opinion, cannot unequivocally be separated from other factors, we have abstained from a correction of the value changes for the third quarter 1997.

14 A property is considered 'new' in the fiscal sense when, it has been sold within the first five years for the first time. In all following transactions the property is considered 'old' (see Sebastian, 1996, p. 12). 
are to be performed for the original sample as well as for all partial samples excluding the problematic factors. To the extent that means and standard deviations as well as the results for the estimations of the coefficients remain robust after reduction of the sample, the sets of data which are incomplete for the characteristics named above will be excluded.

Statements regarding the existence of central heating exist in only 4630 of the cases. This subset displays an obvious change of the distribution parameters. Additionally, insignificant parameter estimates resulted for several variables as a result of the significantly lower number of samples. For this reason, the alternative was chosen of not considering the variable for central heating in the regression equation.

Less unequivocal were the results regarding the existence of a lift. This characteristic is not assessed in 139069 sets of data. For example, excluding these incomplete sets of data result in an increase in average area of about 10 square meters for the smaller sample (see Table 2). Also with reference to other variables slightly higher values were noticeable. However, since the results of the control-regressions did show robust results for the parameter estimates, the exclusion of incomplete sets of data was chosen so that the respective regression could be modeled for the elevator variable.

Some variables, however, as the number of rooms, could not be considered, due to the high correlation to the surface, which may lead to inefficiency of the estimations (see Hoesli and Thion, 1995, p. 81). Socio-economic statements regarding buyer and seller have likewise not been taken into consideration, as these have no direct causal connection to the value of the property (see Edmonds, 1984, p. 80).

For selected characteristics, imputation was used in case of missing observations. Regarding the numbers of parking spots included in the price, it is assumed that, if not mentioned, indeed no parking spots where sold with the apartment. Concerning the existence of gardens or terraces, it seemed justified to make basic assumptions concerning the effect of the quality in spite of a lack of details. Since properties in the center of Paris seldom have gardens or terraces at their disposal, it was assumed in the case of no mention being made of their existence, that none in fact existed.

Samples are often 'cleaned up' using various procedures ${ }^{15}$ through the exclusion of certain characteristics described as being unusually low or high. If such deviates are caused by measuring faults or mistakes in the analysis of the data, their elimination from the sample is uncontroversial. If, however, extreme values exist for a correctly documented regular sales procedure, cleaning up the sample is considered questionable in the relevant scholarship (see Barnett and Lewis, 1984, pp.4-7, 25-27, 178-180). For example, sales prices of less than $€ 150$ per square meter for the residential area of Paris may indicate exceptional sales conditions, or an error in the data analysis. Without additional information, it is impossible to ascertain whether, in

\footnotetext{
15 For an overview, see Barnett and Lewis (1984).
} 
fact, data mistakes or extreme values have been used here. Therefore the application of general cleaning procedures has been avoided. ${ }^{16}$

After excluding transactions which are incomplete with regard to the relevant variables, the sample to be used in the following study is reduced to 84686 sets of data. The following table displays averages and standard deviations for selected attributes of the reduced and the original sample. Additionally, the number of sets of data without details is given in the original sample for the respective characteristic.

\begin{tabular}{|c|c|c|c|c|c|}
\hline \multirow{3}{*}{\begin{tabular}{|l|} 
\\
Price in $1000 €$ \\
\end{tabular}} & \multicolumn{3}{|c|}{$\begin{array}{l}\text { Original sample: } \\
223705 \text { Sets of data }\end{array}$} & \multirow{2}{*}{\multicolumn{2}{|c|}{$\begin{array}{c}\text { Reduced sample: } \\
84686 \text { Sets of data } \\
\text { Averages } \\
\text { (Standard- } \\
\text { deviations) }\end{array}$}} \\
\hline & $\begin{array}{c}\text { Sets of data } \\
\text { without } \\
\text { details }\end{array}$ & \multicolumn{2}{|c|}{$\begin{array}{l}\text { Averages } \\
\text { (Standard- } \\
\text { deviations) }\end{array}$} & & \\
\hline & - & 153 & $(175)$ & 157 & $(164)$ \\
\hline Area in $\mathrm{m}^{2}$ & 31420 & 45.30 & $(36.37)$ & 54.64 & $(34.88)$ \\
\hline Number of toilets & - & 0.75 & $(0.56)$ & 0.86 & $(0.52)$ \\
\hline Number of garages & 16888 & 0.18 & $(0.42)$ & 0.23 & $(0.46)$ \\
\hline $\begin{array}{l}\text { Number of service } \\
\text { rooms }\end{array}$ & - & 0.06 & $(0.32)$ & 0.05 & $(0.29)$ \\
\hline Floors & 6923 & 3.50 & $(2.96)$ & 4.09 & $(3.71)$ \\
\hline Elevator* & 139069 & 0.62 & & 0.62 & \\
\hline Garden* & 88319 & 0.01 & & 0.01 & \\
\hline Terrace* & 87312 & 0.03 & & 0.03 & \\
\hline Construction period & 26557 & & & & \\
\hline Before $1849^{*}$ & & 0.06 & & 0.06 & \\
\hline $1850-1913^{*}$ & & 0.41 & & 0.39 & \\
\hline 1914-1947* & & 0.13 & & 0.14 & \\
\hline $1948-1969 *$ & & 0.11 & & 0.14 & \\
\hline $1970-1980 *$ & & 0.11 & & 0.19 & \\
\hline $1981-1991 *$ & & 0.02 & & 0.03 & \\
\hline $1992-2000 *$ & & 0.04 & & 0.04 & \\
\hline Occupancy & 1140 & & & & \\
\hline Vacant* & & 0.92 & & 0.92 & \\
\hline Partly occupied* & & 0.00 & & 0.00 & \\
\hline Occupied by buyer* & & 0.03 & & 0.03 & \\
\hline Occupied by tenant* & & 0.04 & & 0.04 & \\
\hline
\end{tabular}

* The average of the dummy variables gives the percentage of the sets of data in which the characteristic exists.

TABLE 2. Descriptive statistics.

\footnotetext{
16 With the calculation of the Notaires INSEE index, all transactions were eliminated with a sales price that deviated from the average value in more than two standard deviations (see Dubujet, 2000, p. 3).
} 
The average price for both partial samples is about $€ 152500$ with a standard deviation of a similar amount. Besides the average area, the number of toilets rose slightly from 0.75 to 0.86 . Likewise the values for garages, service rooms and floors increased. The slight changes in the averages of the dummy variables for the existence of elevators, gardens, terraces and the occupancy situation are not displayed due to their being rounded off to two points of a percentage point.

In both samples only a few apartments are constructed predating 1849, 1981-1991 and 1992-2000. A concentration of almost $40 \%$ takes place in the years 1850-1913. The averages of the variables remain almost unchanged, only the construction period $1970-1980$ is overrepresented in the reduced sample with $19 \%$ as opposed to $11 \%$ in the original.

Figure 1 shows the relative distribution of the sample to be used in the following study with reference to the individual arrondissements of the city of Paris. ${ }^{17}$

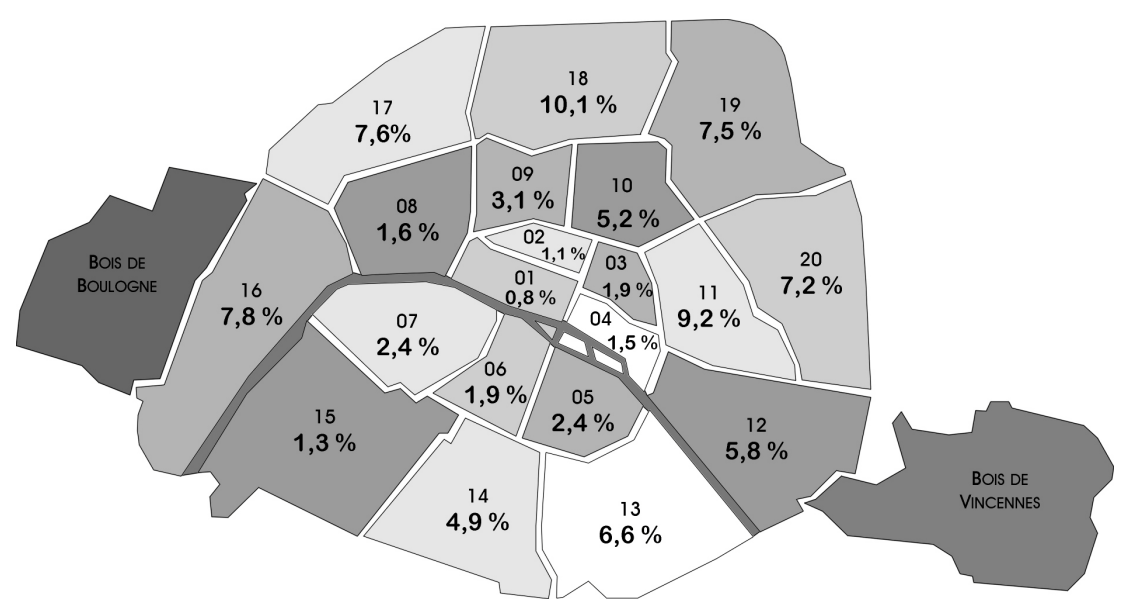

FiguRE 1. Distribution of the reduced sets of data among the arrondissements.

The smaller arrondissements $01-04$ in the down-town area have only a slight percentage of the sample with values between $0.8 \%-1.9 \%$, which is certainly not only due to the relatively small area, but also to the high level of office space in these arrondissements. Most transactions take place in the 15th arrondissement in the south and in the 18th arrondissement in the north of Paris.

\footnotetext{
17 The relative distribution in the original sample is as follows: 1 . arr.: $0.9 \% ; 2$. arr.: $1.5 \%$; 3. arr.: $2.4 \%$; 4. arr.: $1.8 \%$; 5 . arr.: $2.9 \%$; 6 . arr.: $2.3 \%$; 7 arr.: $2.8 \%$; 8. arr.: $1.9 \%$; 9. arr.: $3.6 \%$; 10. arr.: 5.1\%; 11. arr.: 9.0\%; 12. arr.: $5.8 \%$; 13. arr.: $5.4 \%$; 14. arr.: $5.3 \%$; 15. arr.: $10.2 \%$; 16. arr.: $7.5 \%$; 17. arr.: $8.1 \%$; 18. arr.: $10.7 \%$; 19. arr.: $6.1 \%$; 20. arr.: $6.7 \%$.
} 


\section{Estimation of the Regression model Following the Box-Cox TRANSFORMATION}

In order to estimate the regression model, it is necessary to specify the value determining characteristics of the observed real estate transactions. Hereby, apart from the endogenous variable of the sales price, only four other qualities represent metric variables: The surface, the number of garages, the number of bathrooms and the number of service rooms.

All other characteristics indicate conditions and must, therefore, be dealt with as dummy variables. In this connection, four variables directly indicate whether central heating, elevators, terraces or gardens exist. For the characteristic floor location, independent dummy variables are applied for basement and for each of the first five floors above first floor respectively. ${ }^{18}$ For all properties above the seventh floor, a common variable is applied. ${ }^{19}$ Since the first floor was chosen as a reference point for the floor condition, the parameter estimator for the floor dummies gives the surcharge, which is to be paid relative to a property on the first floor. ${ }^{20}$

A modeling of the various qualities according to several dummy variables is then undertaken for the period of construction, the occupancy, the location and the date of sale. In general, the most often occurring condition was chosen as a reference point.

For the location the possibility exists of either choosing a separation into 20 arrondissements or into 80 quartiers. Likewise, the date of sale can be considered monthly or quarterly. ${ }^{21}$ Due to the lengthy calculation involved, monthly dates of sale and consideration of the location as quartiers cannot be contemporaneously modeled. For this reason, quarterly time periods are examined with due consideration of the location in the quartiers. In a second regression, monthly time periods with due respect to the location of the arrondissements are calculated.

The first regression equation includes, therefore, 39 dummy variables for the date of sale (quarterly); 79 for the location (quartiers); four metric variables for the number of bathrooms, garages, and service rooms, as well as for the surface area in $\mathrm{m}^{2}$; one dummy variable for the statement concerning the existence of central heating, elevators, terraces, gardens, seven for the floor locations; six for the construction period; three for the occupancy situation; and finally, a constant. In total, the parameters of $k=143$ variables must be estimated. The second regression equation correspondingly contains 19 dummy variables for the location (arrondissement), and 119 for the month of sale, giving a total of $k=163$ variables. In general, the

\footnotetext{
18 In fact, the floor can be displayed as a metric variable. Such modeling implies, however, that the influence of the location on a higher floor is constant and always identical. The difference between an apartment on the first floor and one on the second floor is, however, certainly larger than one between the 20th and the 21st floor.

19 This implies the assumption that from the eighth floor on, differences in the floor location no longer have significant effects on the price a property will have.

20 For the interpretation of dummy variables, see Halvorsen and Palmquist (1980).

21 As mentioned above, only the direct method using time dummies is applied.
} 
regression equations to be estimated are:

$$
p_{i}^{(\theta)}=\beta_{0}+\beta_{1} s_{i}^{(\lambda)}+\sum_{j=1}^{k} \beta_{i} x_{j i}+u_{i}
$$

where $p_{i}$ represents the property price, $s_{i}$ the property surface area and $x_{j i}$ the other characteristics of the transaction $i$. The latter are not transformed as they could take the value of zero (see Box and Cox, 1964, p. 214).

The maximum likelihood estimation of the parameters results in the parameter estimator $\hat{\theta}=0.11$ and $\hat{\lambda}=0.14$ for the first model (sales timeperiod quarterly, location in quartiers), $\hat{\theta}=0.11$ and $\hat{\lambda}=0.16$ for the second (sales time-period in months, location in arrondissements). For the first model, the optimal model through the Box-Cox transformation following the Equations (3) and (4) thus appears as:

$$
\frac{p_{i}^{0.11}-1}{0.11}=\beta_{0}+\beta_{s} \frac{s_{i}^{0.14}-1}{0.14}+\sum_{j=1}^{143} \beta_{j} x_{j i}+u_{i}
$$

The following table gives the OLS estimators of Equation (7) for the first

\begin{tabular}{|c|c|c|c|c|}
\hline Variable & Coeff. & Variable & \begin{tabular}{|l|} 
Coeff. \\
\end{tabular} & \\
\hline Constant & $16.420 *$ & Floor & 0.166 & $* *$ \\
\hline$\left(\right.$ Surface $\left.^{0.14}-1\right) / 0.14$ & $2.636 *$ & Basement & 0.329 & $*$ \\
\hline Elevator & $0.431 *$ & $2^{\text {nd }}$ floor & 0.509 & $*$ \\
\hline Bathroom & $0.471 *$ & $3^{\text {rd }}$ floor & 0.540 & $*$ \\
\hline Service Room & $0.312 *$ & $4^{\text {th }}$ floor & 0.582 & $*$ \\
\hline Garage & $0.355 *$ & $5^{\text {th }}$ floor & 0.593 & $*$ \\
\hline Garden & $0.443 *$ & $6^{\text {th }}$ floor & 0.543 & $*$ \\
\hline Terrace & $0.566 *$ & from $7^{\text {th }}$ floor & 0.166 & $* *$ \\
\hline New & $0.766 *$ & & & \\
\hline Occupancy & & $\begin{array}{r}\text { Construction } \\
\text { before } 1850\end{array}$ & 0.084 & $*$ \\
\hline Buyer & $-0.954 *$ & $1914-1947$ & -0.069 & $*$ \\
\hline Partial & $-0.516 *$ & 1948-1969 & 0.015 & \\
\hline \multirow[t]{3}{*}{ Tenant } & $-0.976 *$ & 1970-1980 & 0.164 & $*$ \\
\hline & & 1981-1991 & 0.550 & $*$ \\
\hline & & $1992-2000$ & 1.037 & $*$ \\
\hline$R^{2}=0.891$ & & $\begin{array}{l}* * \text { significant o } \\
* \text { significant o }\end{array}$ & $\begin{array}{l}\% \text {-leve } \\
\% \text {-leve }\end{array}$ & \\
\hline
\end{tabular}
regression approach (transaction date as quarter; location as quartiers).

Coefficients omitted here are displayed in the Appendix, Table 5.

TABLE 3. Selected regression results of the Box-Cox model (1990-1999).

The model fits the date with an $R^{2}=89.1 \%$, which is comparable with other studies on hedonic indices. ${ }^{22}$ This is particularly interesting considering the fact that in the data examined here, important details concerning

\footnotetext{
22 See Palmquist (1980, p. 445): 90.0\%; Milton et al. (1984, p. 382): 68\%-76\%; Rasmussen and Zuehlke (1990, p. 432): 96.7\%.
} 
the condition of the building and location are lacking, which are applied in most studies. Sign and size of the regression coefficients are economically intuitively plausible with exception for the positive coefficient for basement. This can be explained by the fact that apartments in basements are typically realized in bourgeois quarters respectively building. The coefficients for all other floors are positive and increase up to the fifth floor. This means, that as the floor location of the building increases, so does the price of the property. Similar results were obtained for the construction year. The negative coefficients show that in the case of occupancy of the property, significant price reductions can be expected.

Almost all parameters are significant at the 1\%-level. Non-significant are the estimates for the construction period 1948-1969, the second quarter of 1992 as well as for the quartiers 39 and 68 [see appendix, Table 5]. This means that no significant price surcharge for these characteristics against each of the reference conditions (construction period 1851-1913; first quarter 1990; quartier 70) could be observed.

The White Heteroskedasticity Test statistic is significant with $W=$ 4984.274. Furthermore, we find significant autocorrelation in the residuals: The first (second, third) order autocorrelation of the residuals: 0.213 (0.150, $0.113)$. Therefore, following Newey and West's (1987) suggestion, $t$-values have been calculated using heteroskedasticity and autocorrelation consistent covariances even if only small changes occur due to the large sample. However, heteroskedasticity and autocorrelation may indicate misspecifications as omitted variables.

\section{Construction of Price indices for the Paris housing Market}

A hedonic index represents the price development of a set of characteristics which can be defined in two different ways. First, the set of characteristics can be allowed to change from one period to another, e.g., if one wishes to estimate the value of a portfolio of apartments which's compositions changes in time. Alternatively, the set of characteristics remains constant in time. As our aim is to track the prices of the apartment segment in the Paris housing market, a constant set of characteristics is appropriate here. Accordingly, the set of characteristics is defined as the average of all objects sold in the period 1990:01-1999:12 (see Table 2 and Figure 1). Therefore, the price indices represent the price of a fictive standardized property portfolio which has, in average, 0.23 garages, is situated to $2.4 \%$ in the 5 th arrondissement, to $2.4 \%$ in the 7 th arrondissement, etc. This fictive property portfolio represents precisely the combination of characteristics traded in the observation period, whose rate changes are observed over time and represents therefore the investment opportunities in the observation period.

The value of the transformed endogenous variable $p_{0}^{(\theta)}$ results from Equation (7). In order to ascertain from this the required value of the original 
variable in the dimension of Euro, the former must first be re-transformed again

$$
p_{0}^{(\theta)}=\frac{p_{0}^{\theta}-1}{\theta} \quad \Leftrightarrow \quad p_{0}=\left(\theta p_{0}^{(\theta)}+1\right)^{1 / \theta}
$$

Since the standard property does not change over time, the value of the transformed variable for the other periods is $p_{0}^{(\theta)}$ plus the hedonic price for the respective year $\beta_{t}$. The untransformed price in period $t$ is therefore:

$$
p_{t}^{(\theta)}=p_{0}^{(\theta)}+\beta_{t} \quad \Leftrightarrow \quad\left\lfloor\theta\left(p_{0}^{(\theta)}+\beta_{t}\right)+1\right\rfloor^{1 / \theta}
$$

A price index is then calculated as follows:

$$
I_{0, t}=\frac{p_{t}}{p_{0}} \cdot 100=\left[\frac{\theta\left(p_{0}^{(\theta)}+\beta_{t}\right)+1}{\theta p_{0}^{(\theta)}+1}\right]^{1 / \theta} \cdot 100
$$

The monthly index values calculated on the basis of the Box-Cox function according to Equation (10) are shown in Figure 2. For comparison, the course of total return indices for stocks and bonds is given, whereby the Datastream Total Return Index was used for stocks, the CAC40, and for hond.

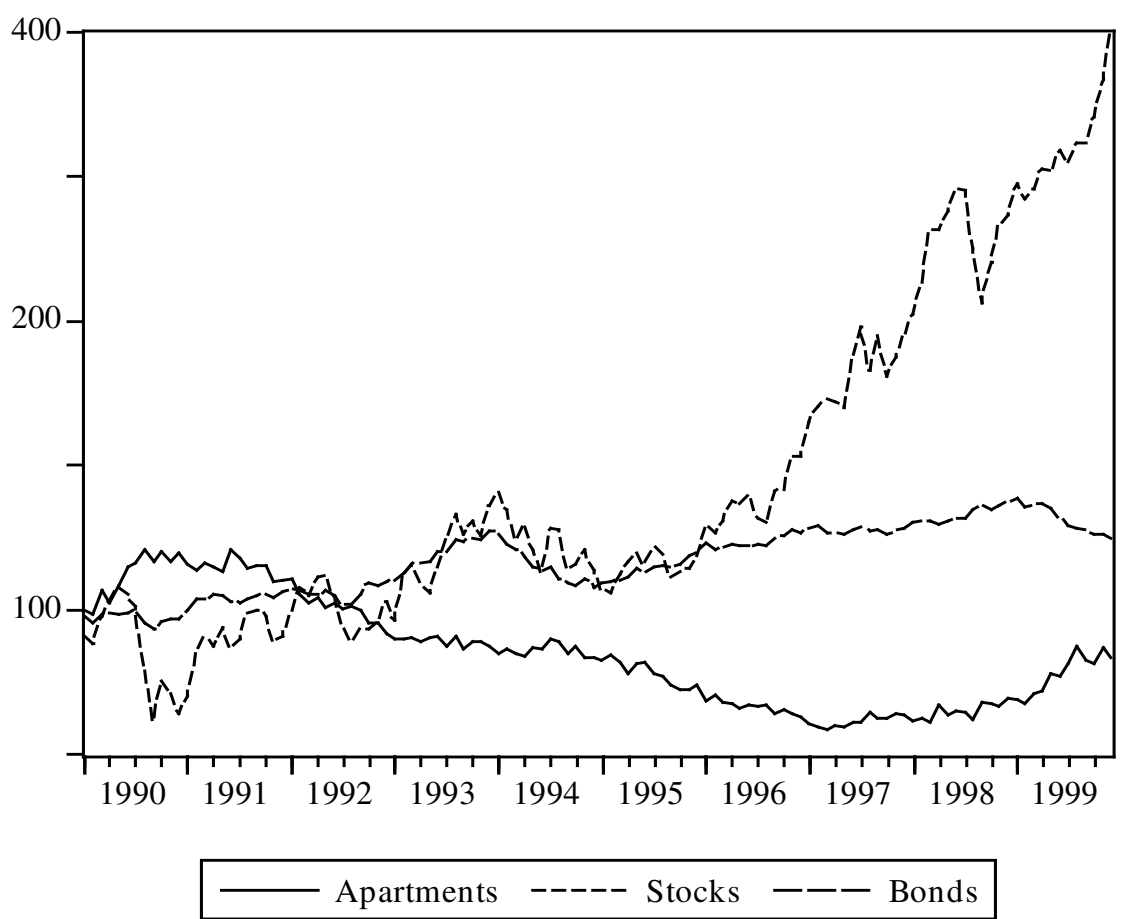

Figure 2. Box-Cox index of apartments compared to total return indices of stocks and bonds. 
The figure reflects the conditions in the Parisian housing market in the $90 \mathrm{~s}$. The phase beginning in the 80 s of continual price increases reached its turning point in 1991, which then led to a seven-year period of falling prices. Since the end of the $90 \mathrm{~s}$, the prices have been once again on the rise. With $I_{t}$ as the value of the index at time $t$, the change rate $r_{t}$ can then be calculated as:

$$
r_{t}=\ln \left(I_{t}\right)-\ln \left(I_{t-1}\right)
$$

Table 4 gives descriptive statistics of the logarithmic changes $r_{t}$ of the indices.

\begin{tabular}{|c|c|c|c|c|c|c|}
\hline & \multicolumn{3}{|c|}{ Monthly value } & \multicolumn{3}{|c|}{ Quarterly value } \\
\hline & Apartments & Stocks & Bonds & Apartments & Stocks & Bonds \\
\hline $\begin{array}{l}\text { Correlation } \\
\text { Apartments }\end{array}$ & 1 & & & 1 & & \\
\hline Stocks & -0.081 & 1 & & 0.038 & 1 & \\
\hline Bonds & -0.094 & $0.441 *$ & 1 & $-0.328 *$ & $0.413 *$ & 1 \\
\hline Average & -0.001 & 0.012 & 0.002 & -0.003 & 0.032 & 0.005 \\
\hline Std. Der. & 0.020 & 0.058 & 0.013 & 0.024 & 0.094 & 0.026 \\
\hline Skewness & 0.548 & -0.460 & -0.240 & 0.803 & -0.341 & -0.507 \\
\hline Autocorr. (1) & $-0.274 *$ & 0.070 & 0.127 & $0.575 *$ & $-0,069$ & 0.153 \\
\hline Autocorr. (2) & 0.099 & -0.123 & 0.034 & 0.252 & -0.124 & 0.039 \\
\hline Autocorr. (3) & $0.259 *$ & -0.003 & 0.114 & 0.265 & 0.060 & -0.103 \\
\hline Observations & 119 & 119 & 119 & 39 & 39 & 39 \\
\hline
\end{tabular}

Correlation coefficients marked with an asterisk are significantly different from zero at the $5 \%$-level.

TABLE 4. Descriptive statistics for apartments (change rate of value index), stocks and bonds (change rate of total return indices).

In the time-period 1990-1999 the value developments for properties was negative and therefore significantly lower than the growth of the TotalReturn-Indices for stocks and bonds returns. Nonetheless a direct comparison between the averages is problematic as the property index only considers value changes. For an equivalent Total-Return-Index, which displays all income flows from property investment, rents are lacking as well as costs. ${ }^{23}$ If one assumes however, that the variances and co-variances would remain constant even under consideration of these returns-components, then the low or even negative correlation to stocks and bonds allows the conclusion to be drawn of a significant diversification potential for an investment in

\footnotetext{
23 Although indices for stocks and bond returns could have been drawn upon for comparison, which as well only register value increases and do not consider other income components (in particular dividends or interest returns). Value increases and income as components of the returns have however very different meanings according to which investment bracket (real estate, stocks, bonds) is considered. The comparability is not increased when only value changes are considered which make up most of the return and which are comparatively low with bonds.
} 
real estate. Regarding the monthly frequencies, the standard deviation of apartments is higher than that of bonds, but less than half of the standard deviation of stock returns. However, for the value changes of the quarterly calculated index, the standard deviation is lowest for apartments. It is furthermore interesting that the value changes of the apartment indices are in contrast to those of the stock and bond indexes - right skewed, indicating as well a lower risk profile of apartments.

Contrary to stocks and bonds, apartments show significant first order autocorrelation for both, monthly and quarterly frequencies and significant third order autocorrelation for monthly frequencies which may be an indication for the lower price efficiency of the real estate market compared to those of stocks and bonds where usually prices can in general not be forecasted easily.

\section{Conclusions AND PERSPECTIVES}

The real estate markets are characterized by various types of market frictions, among them heterogeneity, indivisibility of goods, non-liquidity, a lack of efficiency in information. These specific conditions can be taken into account by hedonic indices on the basis of transaction prices. Due to the high amount of needed data, hedonic indices have not been realized for most markets. For the housing market in Paris however, there exists an internationally unique, publicly available data basis which would allow the construction of a meaningful and reliable hedonic index.

With the approach displayed in this paper, an objective and transparent index is available based exclusively on publicly available data. A wide variety of possible applications is thus opened up. For example insights into the existence of and the length of real estate cycles can be gained through the identification of specific patterns in historical index sequences, which in return bring valuable information for the estimation of price developments in the real estate markets. Institutional investors who hold stock in housing real estate, are hereby provided with an objective benchmark for rate changes. The construction of derivatives on the basis of real estate indices is being discussed as well (see Adam and Venmore-Rowland, 1991; Case et al., 1993; Gehr, 1995; Friggit, 1999). Finally the variances and co-variances to other asset classes can be estimated on the basis of the rate changes shown on the index, and thereby practical knowledge can be won for investment management (see Hoesli and Hamelink, 1996).

\section{REFERENCES}

Adam, A., Venmore-Rowland, P. (1991). Proposed property investment vehicles: Will they work? Journal of Property Investment and Valuation $9287-294$. 
Afifi, A. A., Elashoff, R. M. (1966). Missing observations in multivariate statistics I: Review of the literature. Journal of the American Statistical Association 61 595-604.

Bailey, M. J., Muth, R. F., Nourse, H. O. (1963). A regression method for real estate price index construction. Journal of the American Statistical Association 58 933-942.

Barnett, V., Lewis, T. (1984). Outliers in Statistical Data. 2nd ed., Chichester, New York.

Behring, K., Börsch-Supan, A., Goldrian, G. (1988). Wohnungsnachfrageprognose 1995: Analyse und Prognose der Nachfrage nach Miet- und Eigentümerwohnungen. Duncker \& Humblot, Berlin.

Bender, A. R., Gacem, B., Hoesli, M. (1994). Construction d'indices immobiliers selon l'approche hédoniste. Finanzmarkt und Portfolio Management 8 522-534.

Box, G. E. P., Cox, D. R. (1964). An analysis of transformations. Journal of the Royal Statistical Society 26 211-243.

Case, K. E., Shiller, R. J., Weiss, A. N. (1993). Index based futures and options markets in real estate. Journal of Portfolio Management 19 83-92.

Cassel, E., Mendelsohn, R. (1985). The choice of functional forms for hedonic price equations: Comment. Journal of Urban Economics 18 135-142.

Colwell, P. F., Dilmore, G. (1999). Who was first? An examination of an early hedonic study. Land Economics 75 620-626.

Coulson, N.E., Robins, R.P. (1987). Testing the functional form of statistic appraisal equations. The Appraisal Journal 55 116-125.

Court, A. T. (1939). Hedonic price indices - With automotive examples, The dynamics of automobile demand. 99-117. General Motors Corporation, New York.

Cropper, M. L., Deck, L. B., McConnel, K. E. (1988). On the choice of functional form for hedonic price functions. The Review of Economics and Statistics $70668-676$.

Dempster, A. P., Laird, N. M., Rubin, D. B. (1977). Maximum likelihood from incomplete data via the EM algorithm. Journal of the Royal Statistical Association Series B 39 1-38.

Dubujet, F. (2000). Les indices de prix Notaires-Insee. Unpublished manuscript, 23.03.2000, Paris.

EDMONDS, R. G. JR. (1984). A theoretical basis for hedonic regression: A research primer. AREUEA Journal 12 72-85.

Fisher, J. D., Geltner, D. M., WebB, R. B. (1994). Value indices of commercial real estate: A comparison of index construction methods. Journal of Real Estate Finance and Economics 9 137-168.

FrigGit, J. (1999). Produits dérivés à sous-jacent immobilier - Utilisation des indices notariaux comme sous-jacent de produits dérivés en immobilier d'habitation. Paris, http://www.equipement.gouv.fr.

Gatzlaff, D. H., Haurin, D. R. (1997). Sample selection bias and repeat sales index estimates. Journal of Real Estate Finance and Economics 14 33-49. 
GeHr, A. K. (1995). Applications of derivative instruments. In The Handbook of Real Estate Portfolio Management (J. L. Pagliari, Jr., ed.), 1112-1152. Irwin Professional Pub., Chicago.

Goodman, A. C. (1978). Hedonic prices, price indices and housing markets. Journal of Urban Economics 5 471-484.

Greene, W. H. (1993). Econometric Analysis. 2nd ed., Prentice Hall, New Jersey.

Griliches, Z. (1961). Hedonic price indices for automobiles: An econometric analysis of quality change. The Price Statistics of the Federal Government, General Series No. 73, 137-196. Columbia University for the National Bureau of Economic Research, New York.

HAas, G. C. (1922). Sales Prices as a Basis for Farm Land Appraisal. Technical Bulletin No. 9, St. Paul, The University of Minnesota Agricultural Experiment Station.

Halvorsen, R., Palmquist, R. (1980). The interpretation of dummy variables in semi-logarithmic equations. The American Economics Review 70 474-475.

Halvorsen, R., Pollakowski, H. O. (1981). Choice of functional form for hedonic price equations. Journal of Urban Economics 10 37-49.

Hoesli, M., Gioccotto, C., Favarger, P. (1997). Three new real estate prices for Geneva, Switzerland. Journal of Real Estate Finance and Economics 15 93-109.

Hoesli, M., Hamelink, F. (1996). Diversification of Swiss portfolios with real estate - Results based on a hedonic index. Journal of Property Valuation and Investment 14 59-75.

Hoesli, M., MacGregor, B. D. (2000). Property Investment - Principles and Practice of Portfolio Management. Pearson, Harlow.

Hoesli, M., Thion, B. (1995). Estimation de la valeur locative des appartements: Une étude empirique sur l'agglomération bordelaise. Finance 16 75-87.

HöK, G.-S. (2000). Das französische Grundstücksrecht im Überblick. Grundstücksmarkt und Grundstückswert 10 349-352.

IEIF Institut De L'Epargne ImmobiLiÈre ET Foncière (1999). Investment in French Real Estate. IEIF, Paris.

Kiel, K. A., ZABel, J.E. (1997). Evaluating the usefulness of the American housing survey for creating house price indices. Journal of Real Estate Finance and Economics 14 189-202.

Kuo, C. (1997). A Bayesian approach to the construction and comparison of alternative house price indices. Journal of Real Estate Finance and Economics $14113-132$.

LAFERRÈre, A. (2001). Le nouvel indice de prix Notaire-INSEE. http://www. paris.notaires.fr/fr/immobilier/indices/indice_ notaire_ insee/indice_ notaires_ insee.html, 19.03.2001.

LAnCAster, K. (1966). A new approach to consumer theory. Journal of Political Economy 74 132-157.

Lansink, A. O., Thisssen, G. (1998). Testing among functional forms: An extension of the generalized Box-Cox formulation. Applied Economics 30 1001-1010.

Mark, J.H., Goldberg, M.A. (1984). Alternative housing price indices: An evaluation. AREUEA Journal 12 31-49. 
Maurer, R., Stephan, T., Sebastian, S. (2002). Immobilienindizes im PortfolioManagement. In Investmentmodelle für das Asset-Liability-Modelling von Versicherungsunternehmen: Abschlussbericht der Themenfeldgruppe Investmentmodelle (Fachausschuss Finanzmathematik der Deutschen Gesellschaft für Versicherungsmathematik, Hrsg.), 255-283. Verlag für Versicherungswissenschaft, Karlsruhe.

Milton, J. W., Gressel, J., Mulkey, D. (1984). Hedonic amenity and functional form specification. Land Economics 60 378-388.

NeWEy, W., West, K. (1987). A simple positive semi-definite, heteroskedasticity and autocorrelation consistent covariance matrix. Econometrica 55 703-708.

PAlmquist, R. (1980). Alternative techniques for developing real estate price indices. Review of Economics and Statistics 62 442-448.

Rasmussen, D. W., Zuehlke, T. W. (1990). On the choice of functional form for hedonic price functions. Applied Economics 22 431-438.

Rogers, W. (2000). Errors in hedonic modeling regressions: Compound indicator variables and omitted variables. The Appraisal Journal 68 208-213.

Rosen, S. (1974). Hedonic prices and implicit markets: Product differentiation in pure competition. Journal of Political Economy 82 34-55.

Rubin, D. B. (1976). Interference and missing data. Biometrika 63 581-592.

Schafer, J. L. (1997). Analysis of Multivariate Incomplete Data. Chapman \& Hall, London.

Sebastian, S. (1996). Immobilien-Investment in Frankreich. IEIF, Paris.

Thion, B., Favarger, P., Hoesli, M. (2000). "Repeat Sales", indicateurs de prix et modification de l'environnement immobilier, CD-Rom of Abstracts. 7th European Real Estate Society Conference, 14.-16.06.2000, Bordeaux.

WAugh, F. V. (1929). Quality factors influencing vegetable prices - A statistical study of quality factors influencing vegetable prices in the Boston Wholesale Market. Journal of Farm Economics 10 185-196.

Welsh, S. (1992). The French property investment market. Journal of Property Valuation and Investment 9 65-79.

Wolverton, M.L., Senteza, J. (2000). Hedonic estimates of regional constant quality house prices. The Journal of Real Estate Research 19 235-253.

ZÜRCHER KANTONALBANK (1996). Immobilienmarkt Zürich - Immobilienpreise und Bauinvestitionen unter der Lupe. Zürcher Kantonalbank, Zürich.

Raimond Maurer

Steffen Sebastian

Lehrstuhl für Investment, Portfolio

Management und Alterssicherung

Goethe-Universität

Kettenhofweg 139 (Univ.-Postfach 58)

60054 Frankfurt/Main

RMaurer@wiwi.uni-frankfurt.de sebastian@wiwi.uni-frankfurt.de
Martin Pitzer

Goldman Sachs International

European Equities Peterborough

Court

133 Fleet Street

London EC4A 2BB

United Kingdom

martin.pitzer@gs.com 
ApPEndix

\begin{tabular}{|c|c|c|c|c|c|}
\hline Variable & Coeff. & Variable & Coeff. & Variable & Coeff. \\
\hline II / 90 & $0.199 *$ & \begin{tabular}{|l|} 
Quartier 01 \\
\end{tabular} & $2.033 *$ & Quartier 41 & $-0.081 * *$ \\
\hline III / 90 & $0.486 *$ & Quartier 02 & $1.344 *$ & Quartier 42 & $0.353 *$ \\
\hline IV / 90 & $0.531 *$ & Quartier 03 & $1.648 *$ & Quartier 43 & $0.408 *$ \\
\hline I / 91 & $0.422 *$ & Quartier 04 & $2.102 *$ & Quartier 44 & $0.327 *$ \\
\hline II / 91 & $0.445 *$ & Quartier 05 & $2.434 *$ & Quartier 45 & $0.549 *$ \\
\hline III / 91 & $0.430 *$ & Quartier 06 & $0.981 *$ & Quartier 46 & $0.480 *$ \\
\hline IV / 91 & $0.316 *$ & Quartier 07 & $0.579 *$ & Quartier 47 & $0.231 *$ \\
\hline I / 92 & $0.123 *$ & Quartier 08 & $0.490 *$ & Quartier 48 & $0.563 *$ \\
\hline II / 92 & -0.005 & Quartier 09 & $0.661 *$ & Quartier 49 & $0.911 *$ \\
\hline III / 92 & $-0.083 * *$ & Quartier 10 & $0.944 *$ & Quartier 50 & $-0.385 *$ \\
\hline IV / 92 & $-0.264 *$ & Quartier 11 & $1.746 *$ & Quartier 51 & $0.449 *$ \\
\hline I / 93 & $-0.382 *$ & Quartier 12 & $1.109 *$ & Quartier 52 & $1.362 *$ \\
\hline II / 93 & $-0.370 *$ & Quartier 13 & $1.478 *$ & Quartier 53 & $1.803 *$ \\
\hline III / 93 & $-0.454 *$ & Quartier 14 & $1.880 *$ & Quartier 54 & $1.111 *$ \\
\hline IV / 93 & $-0.436 *$ & Quartier 15 & $1.724 *$ & Quartier 55 & $1.075 *$ \\
\hline I / 94 & $-0.534 *$ & Quartier 16 & $3.594 *$ & Quartier 56 & $0.921 *$ \\
\hline II / 94 & $-0.491 *$ & Quartier 17 & $2.269 *$ & Quartier 57 & $1.097 *$ \\
\hline III / 94 & $-0.434 *$ & Quartier 18 & $1.836 *$ & Quartier 58 & $1.594 *$ \\
\hline IV / 94 & $-0.534 *$ & Quartier 19 & $2.166 *$ & Quartier 59 & $1.439 *$ \\
\hline I / 95 & $-0.606 *$ & Quartier 20 & $2.300 *$ & Quartier 60 & $1.304 *$ \\
\hline II / 95 & $-0.675 *$ & Quartier 21 & $2.852 *$ & Quartier 61 & $1.646 *$ \\
\hline III / 95 & $-0.806 *$ & Quartier 22 & $3.098 *$ & Quartier 62 & $2.160 *$ \\
\hline IV / 95 & $-0.906 *$ & Quartier 23 & $2.523 *$ & Quartier 63 & $2.278 *$ \\
\hline I / 96 & $-1.008 *$ & Quartier 24 & $3.158 *$ & Quartier 64 & $2.295 *$ \\
\hline II / 96 & $-1.086 *$ & Quartier 25 & $3.178 *$ & Quartier 65 & $1.656 *$ \\
\hline III / 96 & $-1.125 *$ & Quartier 26 & $2.781 *$ & Quartier 66 & $1.740 *$ \\
\hline IV / 96 & $-1.201 *$ & Quartier 27 & $2.616 *$ & Quartier 67 & $0.809 *$ \\
\hline I / 97 & $-1.296 *$ & Quartier 28 & $2.536 *$ & Quartier 68 & -0.028 \\
\hline II / 97 & $-1.271 *$ & Quartier 29 & $3.559 *$ & Quartier 69 & $0.287 *$ \\
\hline III / 97 & $-1.219 *$ & Quartier 30 & $2.120 *$ & Quartier 71 & $-1.021 *$ \\
\hline IV / 97 & $-1.192 *$ & Quartier 31 & $2.011 *$ & Quartier 72 & $-1.003 *$ \\
\hline I / 98 & $-1.228 *$ & Quartier 32 & $1.433 *$ & Quartier 73 & $-0.907 *$ \\
\hline II / 98 & $-1.142 *$ & Quartier 33 & $0.567 *$ & Quartier 74 & $-0.888 *$ \\
\hline III / 98 & $-1.104 *$ & Quartier 34 & $0.537 *$ & Quartier 75 & $-0.438 *$ \\
\hline IV / 98 & $-1.054 *$ & Quartier 35 & $0.120 * *$ & Quartier 76 & $-0.066 * *$ \\
\hline I / 99 & $-0.994 *$ & Quartier 36 & $0.447 *$ & Quartier 77 & $-0.439 *$ \\
\hline II / 99 & $-0.805 *$ & Quartier 37 & $-0.295 *$ & Quartier 78 & $-0.349 *$ \\
\hline III / 99 & $-0.593 *$ & Quartier 38 & $-0.271 *$ & Quartier 79 & $-0.123 *$ \\
\hline \multirow[t]{2}{*}{ IV / 99} & $-0.562 *$ & Quartier 39 & 0.031 & Quartier 80 & $-0.160 *$ \\
\hline & & Quartier 40 & $-0.287 * *$ & & \\
\hline
\end{tabular}

TABLE 5. Regression results of the Box-Cox model (1990-1999) [omitted in Table 3]. 


\begin{tabular}{|c|c|c|}
\hline & onth & Index \\
\hline 01 & \multirow{12}{*}{1990} & 100.00 \\
\hline 02 & & 98.89 \\
\hline 03 & & 104.75 \\
\hline 04 & & 101.87 \\
\hline 05 & & 105.94 \\
\hline 06 & & 110.99 \\
\hline 07 & & 112.19 \\
\hline 08 & & 115.57 \\
\hline 09 & & 112.30 \\
\hline 10 & & 115.03 \\
\hline 11 & & 112.44 \\
\hline 12 & & 114.83 \\
\hline 01 & \multirow{12}{*}{1991} & 111.60 \\
\hline 02 & & 110.07 \\
\hline 03 & & 111.82 \\
\hline 04 & & 110.75 \\
\hline 05 & & 109.87 \\
\hline 06 & & 115.47 \\
\hline 07 & & 113.11 \\
\hline 08 & & 110.41 \\
\hline 09 & & 111.42 \\
\hline 10 & & 111.42 \\
\hline 11 & & 107.23 \\
\hline 12 & & 107.42 \\
\hline 01 & \multirow{12}{*}{1992} & 107.94 \\
\hline 02 & & 103.74 \\
\hline 03 & & 101.72 \\
\hline 04 & & 103.22 \\
\hline 05 & & 100.60 \\
\hline 06 & & 101.68 \\
\hline 07 & & 100.18 \\
\hline 08 & & 101.18 \\
\hline 09 & & 99.79 \\
\hline 10 & & 96.95 \\
\hline 11 & & 96.95 \\
\hline 12 & & 94.76 \\
\hline
\end{tabular}

\begin{tabular}{|c|c|c|}
\hline & nth & Index \\
\hline 01 & \multirow{12}{*}{1993} & 93.45 \\
\hline 02 & & 93.31 \\
\hline 03 & & 93.58 \\
\hline 04 & & 92.77 \\
\hline 05 & & 93.72 \\
\hline 06 & & 93.90 \\
\hline 07 & & 91.68 \\
\hline 08 & & 93.98 \\
\hline 09 & & 91.05 \\
\hline 10 & & 92.63 \\
\hline 11 & & 92.72 \\
\hline 12 & & 91.67 \\
\hline 01 & \multirow{12}{*}{1994} & 90.29 \\
\hline 02 & & 91.14 \\
\hline 03 & & 90.23 \\
\hline 04 & & 89.41 \\
\hline 05 & & 91.45 \\
\hline 06 & & 91.13 \\
\hline 07 & & 93.15 \\
\hline 08 & & 92.62 \\
\hline 09 & & 90.25 \\
\hline 10 & & 91.66 \\
\hline 11 & & 89.33 \\
\hline 12 & & 89.15 \\
\hline 01 & \multirow{12}{*}{1995} & 88.76 \\
\hline 02 & & 89.82 \\
\hline 03 & & 88.18 \\
\hline 04 & & 86.05 \\
\hline 05 & & 87.97 \\
\hline 06 & & 88.38 \\
\hline 07 & & 86.00 \\
\hline 08 & & 85.36 \\
\hline 09 & & 83.54 \\
\hline 10 & & 82.67 \\
\hline 11 & & 82.72 \\
\hline 12 & & 83.66 \\
\hline
\end{tabular}

TABLE 6. Hedonic price index for apartments in Paris (monthly, considering location with arrondissements) [Part 1]. 


\begin{tabular}{|c|c|}
\hline Month & Index \\
\hline \multirow{12}{*}{1996} & 80.60 \\
\hline & 81.50 \\
\hline & 80.15 \\
\hline & 79.84 \\
\hline & 79.20 \\
\hline & 79.51 \\
\hline & 79.50 \\
\hline & 79.58 \\
\hline & 78.11 \\
\hline & 78.71 \\
\hline & 77.92 \\
\hline & 77.60 \\
\hline \multirow{12}{*}{1997} & 76.10 \\
\hline & 75.63 \\
\hline & 75.06 \\
\hline & 75.91 \\
\hline & 75.54 \\
\hline & 76.49 \\
\hline & 76.48 \\
\hline & 78.16 \\
\hline & 77.28 \\
\hline & 77.14 \\
\hline & 77.88 \\
\hline & 77.84 \\
\hline
\end{tabular}

\begin{tabular}{|c|c|}
\hline Month & Index \\
\hline \multirow{12}{*}{1998} & 76.79 \\
\hline & 77.29 \\
\hline & 76.42 \\
\hline & 79.52 \\
\hline & 77.79 \\
\hline & 78.46 \\
\hline & 78.39 \\
\hline & 77.02 \\
\hline & 80.15 \\
\hline & 79.99 \\
\hline & 79.34 \\
\hline & 81.10 \\
\hline \multirow{11}{*}{1999} & 80.76 \\
\hline & 79.88 \\
\hline & 81.96 \\
\hline & 82.33 \\
\hline & 85.78 \\
\hline & 85.19 \\
\hline & 87.98 \\
\hline & 91.58 \\
\hline & 88.64 \\
\hline & 88.13 \\
\hline & 91.30 \\
\hline 12 & 89.38 \\
\hline
\end{tabular}

TABLE 6. Hedonic price index for apartments in Paris (monthly, considering location with arrondissements) [Part 2].

\begin{tabular}{|rr|r|}
\hline \multicolumn{2}{|c|}{ Quarter } & Index \\
\hline I & & 100.0 \\
II & \multirow{2}{*}{1990} & 104.4 \\
III & & 111.1 \\
IV & & 112.2 \\
\hline I & & 109.6 \\
II & \multirow{2}{*}{1991} & 110.2 \\
III & & 109.7 \\
IV & & 107.0 \\
\hline I & & 102.6 \\
II & \multirow{2}{*}{1992} & 99.8 \\
III & & 98.2 \\
IV & & 94.4 \\
\hline I & & 92.0 \\
II & \multirow{2}{*}{1993} & 92.2 \\
III & & 90.5 \\
IV & & 90.9 \\
\hline I & & 88.9 \\
II & \multirow{2}{*}{1994} & 89.8 \\
III & & 90.9 \\
IV & & 88.9 \\
\hline
\end{tabular}

\begin{tabular}{|rr|r|}
\hline \multicolumn{2}{|c|}{ Quarter } & Index \\
\hline I & & 87.5 \\
II & \multirow{2}{*}{1995} & 86.2 \\
III & & 83.7 \\
IV & & 81.8 \\
\hline I & & 80.0 \\
II & \multirow{2}{*}{1996} & 78.6 \\
III & & 77.9 \\
IV & & 76.6 \\
\hline I & & 75.0 \\
II & \multirow{2}{*}{1997} & 75.3 \\
III & & 76.4 \\
IV & & 76.7 \\
\hline I & & 76.2 \\
II & \multirow{2}{*}{1998} & 77.6 \\
III & & 78.2 \\
IV & & 79.2 \\
\hline I & & 80.2 \\
II & \multirow{2}{*}{1999} & 83.7 \\
III & & 87.7 \\
IV & & 88.3 \\
\hline
\end{tabular}

TABLE 7. Hedonic price index for apartments in Paris (quarterly, considering location according to quartier). 